\title{
QUESTÕEs DA LÓGICA DA PESQUISA CIENTÍFICA OU UM EXERCÍCIO DE METODOLOGIA DOGMÁTICA
}

\author{
Mario Brockmann Machado'
}

Palavras-Chave

Método científico

\section{SUMÁRIO}

1. Introdução

2. Conceitos

3. Indicadores

4. Sentenças

5. Hipóteses

6. Leis e teorias

7. Explicação e expedição

8. Conclusões
"When I use a word, Humpty Dumpty said, in rather a scornful tone, it means just what I choose it to mean - neither more nor less.

The question is, said Alice, whether you can make words mean so many different things.

The question is, said Humpty Dumpty, which is to be master - that's all."

Lewis Carroll, Through the Looking Glass

\section{Resumo}

O objetivo deste texto é analisar temas fundamentais do método científico, a saber: conceitos, definições, indicadores, sentenças, hipóteses, leis e teorias, explicação e predição. Excetuada a discussão sobre "indicadores", não reivindico originalidade, minha intenção tendo sido a de elaborar uma síntese, reconhecidamente heterodoxa, livremente inspirada na filosofia da ciência do positivismo lógico do Círculo de Viena e nas tradições inglesas do empirismo e da filosofia analítica, conforme esclarecido ao final. 


\title{
LOGIC QUESTIONS OF SCIENTIFIC RESEARCH OR AN EXERCISE OF DOGMATIC METHODOLOGY
}

\author{
Mario Brockmann Machado
}

\section{Keyword}

scientific method

\section{Summary}

Some major problems in the philosophy of science, namely concepts, hypotheses, laws, theories, causes, explanation and prediction, are examined in this article according to the (freely interpreted) tradition of logical empiricism. The author illustrates the discussion by referring to the literature on political development. Language has two kinds of terms: logical and descriptive ones. The descriptive or extra-logical terms may be either proper names or property words. The latter are also called concepts. Concepts refer to properties (or relations), which are exemplified by facts and events in the world. Concepts may be either primitive or defined. The meaning of defined concepts is usually introduced by definitions, through the specification of the properties to which the concept refers. Definitions are conventions: they are not discovered, but created. They should be both empirically precise and theoretically significant. Concepts are created in order to be used in hypotheses, so that concept formation and theory building cannot be treated separately. Lack of precision in definitions has lead authors to search for "indicators". However, once concepts are precisely defined, there is no need to deal with "indicators": all one has to do is to see whether the properties specified in the definition are exemplified or not by facts and events in the world. The search for "indicators" simply reflects the need of properly stated definitions. Hypotheses are generalized propositions of the kind "if ... then", which relate two or more concepts. Since they are expressed by synthetic sentences, they are true of false according to the way the world is perceived. Depending on the quality and quantity of available direct and indirect evidence, a hypothesis can be accepted beyond reasonable doubts. If accepted, it is called a law. Causal laws are special kinds of law: they asymmetrically specify a temporal sequence between its concepts. A theory is a deductively related body of laws. The explanation of a fact or event consists in subsuming it under a law, or laws. Likewise, laws with a low level of generalization are explained when subsumed under laws with a higher level of generalization. The logical structure of prediction is not basically different from that of explanation, especially when universal laws are involved. The search for causal laws and for theories that integrate them is the most important aim of empirical sciences, for if we know the causes and effects of phenomena, then it is possible, at least in principle, to interfere with them. Finally, the author calls attention to the difference between the task of logically reconstructing science and that of constructing science. The former may be helpful to the latter, but it should be used with care so that it does not raise obstacles to the development of science. 


\section{Introdução}

As ciências empíricas procuram descrever, explicar e predizer a ocorrência de fatos e eventos no mundo. A linguagem é, evidentemente, um ingrediente essencial dessa tarefa.

As linguagens possuem um estoque de termos (vocabulário) e regras que orientam a utilização desses termos (gramática), de modo a possibilitar a sua combinação em sentenças.

\section{Conceitos}

Existem dois tipos distintos de termos: lógicos e descritivos. São exemplos de termos lógicos: e, mas, não, todos, se...então, etc. Por sua vez, os termos descritivos, ou extralógicos, são nomes próprios (Brasil) ou nomes de propriedades (país). É possível, agora, especificar o objeto da presente reflexão: apenas nomes de propriedades, ou conceitos, serão considerados, já que nomes próprios não devem ser usados no discurso científico.

Conceitos referem-se a propriedades (ou relações), que são exemplificadas por fatos ou eventos no mundo natural ou social. Conceitos podem ser primitivos ou definidos. Os significados dos conceitos definidos, como já indica o nome, são idealmente introduzidos por meio de definições, que utilizam termos lógicos, conceitos primitivos e conceitos já definidos. Assim, por exemplo, "desenvolvimento político" seria um conceito definido.

Quando perguntamos pelo significado de um conceito (O que é X?), é possível escolher entre duas respostas. Uma procura identificar a "essência" de X, a sua natureza: X é... Esta é uma definição real. Tal procedimento é seguidamente encontrado na bibliogra- fia relativa a desenvolvimento político. Esse "método essencialista da ciência", como o chamou Popper ${ }^{2}$ (bem distante do nominalismo), só pode levar a decepções, pois como pode alguém ter certeza de que "descobriu" o "verdadeiro" significado de um conceito? De fato, será sempre possível a qualquer autor afirmar que a sua é a verdadeira definição. Como resultado, teríamos uma discussão infindável de definições, cada autor criticando todas elas do ponto de vista da sua. Assim, a tarefa de definir conceitos se transformaria em um fim em si mesmo e o progresso científico entraria em compasso de espera.

Para sair desse impasse, é preciso dar um passo atrás: antes de se tentar esclarecer o significado de $X$, é necessário perguntar $O$ que é 'O que é $X$ ?’? Este raciocínio nos permite formular a questão de uma maneira mais promissora: a tarefa passa a consistir em identificar o(s) uso(s) linguístico(s) da palavra ' $X$ ' em algum discurso (neste caso, no discurso filosófico). Dessa forma, a resposta seria: ' $X$ ' significa... Esta é uma definição nominal (que será adotada neste texto). Ela permite a indicação da propriedade ou das propriedades às quais o conceito se refere.

Tanto faz se o conceito em definição é novo, isto é, se está sendo introduzido no vocabulário pela primeira vez, ou antigo, isto é, se está sendo redefinido. Embora seja possível distinguir entre essas duas operações, isso não é necessário. Na verdade, não seria inteiramente correto fazê-lo, pois, como o significado de um conceito definido lhe é atribuído por sua definição, redefinir um

${ }_{2}^{2}$ Popper, Karl, The Logic of Scientific Discovery, Nova York: Harper \& Row, 1965 [1935] [A lógica da pesquisa científica, trad. Leonidas Hegenberg e Octanny Silveira da Mota, São Paulo: Cultrix, $3^{a}$ ed. 1985 (7 ed.1998)]. Popper não era um seguidor do positivismo lógico, embora seu pensamento tivesse com ele muita afinidade, mas meu objetivo aqui não era resumir as ideias dessa escola sobre o método científico, e sim apresentar a síntese que, por ela influenciada, elaborei livremente para meu próprio uso, por heterodoxa que fosse. 
conceito implica mudar o seu significado, o que equivale a introduzir um novo conceito.

Entretanto, nem todos os conceitos de um vocabulário podem ser introduzidos por definição, pois isto levaria a uma regressão infinda. Para romper tal círculo, é necessário que alguns conceitos sejam introduzidos de forma extralinguística, por meio de algum tipo de relacionamento direto de um observador com uma exemplificação empírica das propriedades por eles referidas (Os significados das diferentes cores, por exemplo, não são entendidos por um cego de nascença).

Alguns autores argumentam que outros métodos de introdução de conceitos podem também ser utilizados. Carnap costumava falar em "sentenças reducionistas"; Hempel mencionava tipos de "sentenças interpretativas". Wittgenstein, sempre um caso à parte, apresentava, em seu Tratado Lógico-Filosófico, posição aparentada com a aqui exposta, mas nas Investigações Filosóficas abriu caminho para uma abordagem mais flexível no que se refere à tarefa de identificar significados de conceitos, sem, no entanto, deixar de entender a filosofia como, por assim dizer, uma atividade terapêutica, cujo objetivo é chamar a atenção para as armadilhas que resultam do uso desatento da linguagem. Mas a discussão dessa problemática já escapa ao plano desta reflexão, porque é preciso distinguir entre as duas seguintes perguntas: Existem meios de atribuir significado a conceitos, além dos dois básicos mencionados? E, mesmo que existam, acaso o estado presente de uma ciência não deve ser considerado, antes que se decida por sua utilização? A primeira pergunta envolve um problema próprio de filosofia da ciência e muito se tem dito sobre o assunto. A segunda é de ordem estritamente pragmática. No caso da ciência po- lítica, como também no de outras ciências sociais, parece já existir suficiente confusão a respeito da formação de conceitos. No momento, e no futuro próximo, seria aconselhável tratar com conceitos definidos. E bem definidos.

O significado de um conceito é atribuído por estipulação. Portanto, não faz sentido discutir a verdade ou a falsidade de uma definição nominal. Definições são convenções. Isto não significa, entretanto, que todas as definições sejam igualmente relevantes. Existem critérios para julgar definições.

Assim, uma definição deve ser empiricamente precisa, isto é, deve identificar com clareza a propriedade à qual o conceito por ela introduzido pretende referir-se, de tal forma que suas exemplificações empíricas sejam identificáveis. Em segundo lugar, é de se esperar que uma definição seja teoricamente relevante, isto é, que o conceito por ela introduzido contribua para a melhor compreensão de um assunto específico qualquer, por meio de sua utilização em hipóteses, leis e teorias. Dessa forma, um conceito definido deve ter um claro conteúdo empírico e uma razoável relevância teórica.

Mas essas duas qualificações não interferem na noção básica de que, sendo introduzidos convencionalmente, os conceitos significam apenas aquilo que foram criados para significar. No caso de conceitos definidos, seus significados consistem naquilo que suas definições estipulem e nada mais. Em suma, todo o significado de um conceito definido reside em seu definiens: definiemdum $=(p f)$ definiens.

Um resumo dessa discussão pode agora ser oferecido: o significado de um conceito científico não é descoberto, e sim criado. Perguntar pelo significado de um conceito 
é, via de regra, perguntar por uma definição. Assim, para responder a perguntas do tipo "O que é desenvolvimento político?", não é necessário procurar coisa alguma, como se o seu significado estivesse escondido na realidade. É suficiente oferecer uma definição empiricamente precisa e, é de se esperar, teoricamente relevante. Quando um conceito bem definido revela-se relevante, então é possível dizer, como notou Bergmann, que o "descobrimento" de um conceito foi um passo decisivo para o descobrimento (sem aspas) de leis e teorias 3 .

\section{Indicadores}

Ocorre seguidamente que autores desistem da tarefa de definir conceitos e passam a falar em "indicadores". A literatura sobre desenvolvimento político, como a das ciências sociais em geral, está repleta deles. Presumem esses autores a existência de uma "dimensão subjacente" cuja essência é tão difícil de ser entendida, que não se pode defini-la, mas apenas fazer referência a ela de forma parcial e indireta, por meio de seus "indicadores".

O problema passa então a ser o do significado de "dimensão subjacente", e podemos apontar duas variantes: a primeira diz respeito ao problema de definições reais, sendo o leitor remetido às observações sobre o assunto já formuladas acima; a segunda, muito comum, diz respeito à soma total de opiniões expressas por autores sobre um conceito qualquer. Em outras palavras, falase tanto sobre um dado conceito que, em pouco tempo, ele de fato adquire uma enorme "dimensão subjacente", isto é, a soma de tudo o que se disse sobre ele. Quando um autor deseja definir tal conceito, passa a fi-

\footnotetext{
Bergmann Gustav Philosophy of Science. The University of Wisconsin Press, 1957, p. 51. A filosofia de Bergmann, em geral, não era positi vista, mas a sua filosofia da ciência, sim.
}

car em dúvida sobre o que incluir e o que excluir. Pode entender, talvez, que algo será perdido, se não se incluir tudo. Ele decidirá, então, falar sobre alguns dos indicadores do conceito, querendo com isto dizer que subsistem ainda outros aspectos de tal dimensão subjacente a serem analisados. Situação semelhante surge, por exemplo, quando se tem um insight sobre determinado assunto e se passa à tarefa de definir os conceitos envolvidos.

Mas definições de conceitos não são resumo de opiniões, nem descrição de insights. Ambos os problemas resultam de uma compreensão imprecisa da finalidade das definições nas ciências empíricas, isto é, introduzir conceitos para serem utilizados em hipóteses. Quando a definição é elaborada, tudo o que se requer é precisão, pois a relevância teórica do conceito definido depende inteiramente da empiria percebida. Se ele não mostra ser relevante, isto é, se não se descobre qualquer generalização que o relacione com outros conceitos bem definidos, ele terá de ser abandonado, pouco importando a quantidade de trabalho que o autor tenha tido com a sua definição.

Igualmente sem sentido é a discussão sobre bons e maus indicadores de um conceito, porque, para julgá-los de uma ou de outra forma, é preciso compará-los a algo. Mas esse algo é apenas o significado que o autor pretende dar ao conceito e que ele mantém vagamente formulado em seus pensamentos. Uma vez explicitado esse significado em uma definição clara, desaparece a necessidade de falar em indicadores: restará, então, verificar se a(s) propriedade(s) indicada(s) na definição do conceito são ou não exemplificadas por fatos ou eventos no mundo. A busca de indicadores apenas expressa, de forma pouco precisa, a necessidade de boas 
definições. Apesar disso, a "operacionalização" de conceitos e a busca de indicadores são um procedimento tão enraizado, que muitos pesquisadores continuarão a assim proceder. Na prática, isso é compreensível, mas, reitero, desde que se leve em conta que as associações e correlações eventualmente encontradas entre esses indicadores e outras variáveis nada nos dizem sobre aquela vaga definição "teórica" de que falei acima. Proceder de maneira contrária seria logicamente inválido.

Vale a pena insistir nessa temática, abordando-a sob outro ângulo. Para esses autores, a definição de um conceito seria feita em dois passos: a) define-se "teoricamente" o conceito, o que na prática se traduz em uma definição vaga e imprecisa; e b) procuram-se indicadores para dar conteúdo empírico à definição. Sobre isto, pelo menos dois comentários podem ser feitos: a) não faz sentido falar em definições teóricas, e sim, em alguns casos, em definições de termos teóricos (também chamados de abstratos), como se verá adiante, o que é coisa diversa, e que, de qualquer forma, não se confunde com más definições; e b) o que eventualmente se relacionará em generalizações empíricas com outras variáveis são os indicadores, e não o vago definiens da definição "teórica", sobre o qual nada se poderá afirmar logicamente. Tal definiens torna-se, portanto, inútil, não havendo razão para mantê-lo. Deve ser abandonado, sendo substituído pelos indicadores, que passariam a ser o definiens de fato da definição.

Desta forma, em vez de a definição conter três elementos, isto é, definiendum, definiens e indicadores, ela passaria a ter apenas dois: definiendum e definiens (= indicadores), podendo agora o termo 'indicador' ser abandonado, por inútil.
Esta problemática pode ser exemplificada fazendo-se uma breve referência a uma celeuma que se estabeleceu, entre certos autores norte-americanos, sobre as definições de democracia e desenvolvimento político, em estudos que procuravam examinar quantitativamente suas relações com o desenvolvimento econômico ${ }^{4}$.

Cutright, ${ }^{5}$ por exemplo, afirmou que "o grau de desenvolvimento político de uma nação pode ser definido pelo grau de complexidade e especialização de suas instituições políticas nacionais". Seria fácil prever que definição tão imprecisa criaria problemas. De fato, isto ocorreu, e o autor então resolveu construir um índice de desenvolvimento político que, como geralmente ocorre, baseou-se em critérios (indicadores) não mencionados na definição. No caso, Cutright utilizou a representação de dois ou mais partidos no Parlamento e a eleição popular do chefe do Executivo, o que, tecnicamente, deveria ser tomado como uma nova definição de 'desenvolvimento político', visto ser distinta da anterior.

Neubauer, ${ }^{6}$ o continuador do debate, não poderia deixar de notar a disparidade entre a definição e o índice de Cutright, afirmando que este se referia a desenvolvimento político democrático. Apesar disso, sustentou Neubauer que o desenvolvimento político democrático não poderia ser adequadamente medido pelo índice de Cutright, e que a utilização de "um índice mais adequado" (o dele) levaria a resultados diversos. $\mathrm{Na}$ realidade, todo o problema aqui reside em que Neubauer, com o seu novo índice, es-

${ }^{4}$ Machado, Mario Brockmann, "Desenvolvimento político: uma revisão bibliográfica", Cadernos da PUC-Rio, ago. 1971, p. 90-134.

${ }^{5}$ Cutright, Phillip, "National political development - its measurement and social correlates", in Polsbi et al. (orgs.), Politics and Social Life, Boston: Houghton Mifflin, 1963, p. 569-82.

Neubauer, Deane, "Some conditions of democracy", American Political Science Review, vol. 61, n. 4, 1967, p. 1002-9. 
tava de fato redefinindo 'desenvolvimento político'. Necessariamente, suas conclusões teriam de divergir das de Cutright. Teriam de divergir por estarem os dois autores falando de propriedades diversas do sistema político, apesar de utilizarem o mesmo termo, a saber, 'desenvolvimento político', para nomeá-las. Este termo simplesmente não tem o mesmo significado nos dois artigos, pois o que Neubauer chama de "um índice mais adequado" nada mais é do que a sua definição de 'desenvolvimento político'.

Por fim, Needler ${ }^{7}$ afirma que os dois autores anteriores não souberam resolver a questão e se propõe a fazê-lo. Identifica, então, desenvolvimento político com "democracia estável" e repete exatamente o mesmo procedimento metodológico defeituoso cometido pelos outros autores: elabora um novo índice, baseado em novos indicadores, para medir um conceito cuja definição continuava tão vaga e imprecisa quanto no começo do debate.

Esta breve exemplificação parece mostrar que a falta de cuidado com o primeiro e mais básico passo da análise científica - a formação de conceitos - pode levar a uma situação de incompreensão entre investigadores sociais e a uma grande perda de tempo, tanto do autor quanto do leitor.

Além dessa falha metodológica básica, um problema muito comum e sério com autores que utilizam indicadores é o perigo de enormes ambiguidades: como o significado de conceitos não é explicitado claramente é comum encontrá-lo com significados diversos em um mesmo texto.

Por último, existem autores que falam de conceitos abstratos. 'Desenvolvimento po-

7 Needler, Martin, "Political development and socioeconomic devel opment: the case of Latin America", APSR, vol. 62, n. 3, 1968, p. 889-97. lítico' seria um exemplo desse tipo de conceito. Mas, se um conceito abstrato não é tomado como sinônimo de um conceito definido (em oposição a primitivo), qual é o significado desse termo? Ora, como o definiens de uma definição é permutável com o seu definiendum, se o definiens tem conteúdo empírico (seja por referência direta a propriedades exemplificadas, seja por referência indireta, por meio de uma cadeia de definições), então também o terá o seu definiendum. O importante é não confundir conteúdo empírico com existência física, já que são questões diversas. De qualquer maneira, como notou Bergmann, o problema aqui não diz respeito à existência ou não do referente de um dado conceito definido (pois 'existir' é um conceito irrecuperável para as ciências empíricas, consideradas as suas conotações metafísicas), mas, sim, de saber se a propriedade referida pelo conceito é ou não exemplificada empiricamente. ${ }^{8}$ Caso o seja, poderá então haver lugar para tal conceito no vocabulário das ciências empíricas, dependendo de sua relevância teórica.

Convém ressaltar que, embora isto fosse idealmente desejável, para evitar armadilhas metafísicas, nem todos os conceitos definidos referem-se a propriedades diretamente observáveis (elétrons, por exemplo). Seriam, talvez, "ficções convenientes". Mas é necessário que as teorias que incluírem esses conceitos permitam a dedução de hipóteses empiricamente observáveis e testáveis.

Parece, portanto, que uma definição de 'desenvolvimento político' deveria identificar com clareza certas propriedades (ou relações) do sistema político, a não ser, evidentemente, quando se usa esse termo não para referir propriedades que possam even-

Bergmann Gustav op cit p. 53. Ver também do mesmo autor "The logic of psychological concepts", Philosophy of Science, vol. 18, 1951, p. 93-110. 
tualmente relacionar-se em generalizações, e sim para nomear uma ampla área de estudos, de contornos não claramente delineados, quando então a crítica aqui a presentada deixaria de ter sentido. Mais precisamente, tal definição deveria especificar que tipos de modificação, em que propriedades do sistema político, poderiam ser tomadas como instâncias de 'desenvolvimento político'. Em geral, esse conceito tem sido utilizado para fazer referência, muito vagamente, a tipos especiais de mudança, tais como a otimização do desempenho do sistema político, a maximização de suas capacidades etc. Essas definições, embora sugestivas, carecem de precisão. Mas poderiam, sem dúvida, ser refinadas, e até mesmo quantificadas. Certamente, não há obrigatoriedade deste último passo, pois toda a discussão sobre desenvolvimento político pode ser mantida em nível nominal ou qualitativo. Mas a quantificação, tal como no caso do desenvolvimento econômico, traz grandes vantagens. Quantitativamente, um sistema político muda quando os valores de seus componentes sofrem alterações. A importância da mudança depende da importância que o componente cujo valor esteja sendo alterado possua no sistema, bem como da magnitude dessa alteração. A distinção entre mudança no sistema e mudança do sistema poderá também ser especificada. Dessa forma, uma definição de 'desenvolvimento político' deveria identificar claramente que tipo de mudança se pretende significar com o uso de tal conceito. Provavelmente, a definição especificará que nem todo tipo de alteração na propriedade referida pelo conceito será tido como sua exemplificação, mas apenas certos tipos de alteração, que terão de ser explicitados. Por exemplo: o aumento dos valores das propriedades, mas não o decréscimo desses valores, na unidade de tempo escolhida.
É preciso notar, por outro lado, que 'desenvolvimento político' não precisa ser necessariamente definido por meio de referências diretas a propriedades do sistema político: tal conceito pode ser definido por meio de outros conceitos já definidos. É este o caso, por exemplo, de definições comuns de 'desenvolvimento econômico'. E, como no caso deste conceito, caso se pretenda determinar o nível de desenvolvimento político de qualquer sistema, a qualquer momento, o que se requer é verificar o valor daquilo que é expresso no definiens de 'desenvolvimento político', ou seja, é preciso medi-lo. De resto, tanto mais teoricamente relevante será a definição oferecida quanto mais regularidades forem descobertas relacionando tal conceito a outros igualmente bem definidos, de natureza política ou não.

\section{Sentenças}

É através de sentenças que se realiza o ato do discurso. É possível diferenciá-las em dois tipos, de acordo com o que proponham: analíticas ou sintéticas. (Esta divisão, de inegável utilidade prática, apresenta, no limite, problemas de solução muito difícil, talvez impossível.) Por outro lado, tais sentenças podem ser verdadeiras ou falsas. Para decidir se uma sentença analítica é verdadeira ou falsa, é suficiente analisar logicamente seus termos e suas inter-relações. Isto significa que elas são logicamente verdadeiras ou falsas: tautologias ou contradições, respectivamente. Nisso diferem de sentenças sintéticas, cuja verdade ou falsidade pode ser estabelecida apenas por meio da referência a fenômenos empíricos. Portanto, elas são empiricamente verdadeiras ou falsas. A rejeição dos chamados "juízos sintéticos a priori" está, assim, na base da posição 
metodológica aqui exposta (Utilizo o critério semântico de verdade: assim, verdadeiro e falso são predicados de sentenças).

\section{Hipóteses}

Sentenças sintéticas, ou empíricas, podem ser utilizadas para descrever fatos ou eventos. Elas podem também ser usadas para propor hipóteses. Hipóteses são proposições generalizantes do tipo "se...então", que relacionam dois ou mais conceitos. É conveniente distinguir entre hipóteses sobre fatos ou eventos e hipóteses sobre leis. Em ambos os casos, elas constituem suposições sobre o mundo, mas de uma natureza distinta. 0 termo 'hipótese', porém, costuma ser usado para referir-se a suposições sobre leis.

Sendo expressas por sentenças sintéticas, a verdade ou falsidade das hipóteses só podem ser determinadas por meio de referência a fenômenos empíricos.

Conforme o que foi dito, hipóteses sobre desenvolvimento político consistiriam em proposições generalizantes, do tipo "se...então", que relacionassem as propriedades por ele referidas a outras, de natureza política ou não. (Uso 'sentença' como sinônimo de 'proposição').

A identificação de conceitos estratégicos e os seus relacionamentos em hipóteses baseiam-se em conhecimentos prévios do investigador. Parece não ser possível derivar hipóteses logicamente da simples observação de fatos ou eventos: esta transição requer imaginação criadora, individual ou coletiva. O exame das operações mentais que levam à formulação de hipóteses é de interesse da ciência, e não da filosofia da ciência. E, mesmo que existissem tais regras de formulação de hipóteses, estas não po- deriam ser dispensadas de sua verificação empírica.

Também é preciso distinguir entre os contextos do descobrimento e da validação. Não existe uma lógica do descobrimento, e sim da validação. Os processos mentais e sociais que conduzem ao descobrimento são, como tais, alheios à lógica da validação. Tal como no caso da formulação de hipóteses, eles constituem, como temas empíricos, objetos de estudo da ciência. Nem muito menos se deve confundir a lógica da validação, isto é, o chamado "método científico", com as técnicas de investigação científica.

O fato de muitas hipóteses e descobrimentos em ciências sociais serem resultado de um insight empático do investigador não deve confundir o assunto: tal fenômeno constitui um tema interessante para um estudo psicológico, mas não, como já se sugeriu, para a análise da lógica das ciências sociais, pois o que então importa é o que se segue ao insight, isto é, a sua validação.

De certa forma, a problemática posta pela chamada "sociologia compreensiva" se vincula ao acima dito. Sustentam os autores dessa orientação que uma sociologia que se preocupasse com conhecer o "sentido mentalizado" da ação do autor necessitaria de uma metodologia diversa da utilizada nos demais ramos das ciências empíricas. Mas, como saber se o insight empático do investigador sobre o significado da ação é ou não verdadeiro? É óbvio que, enquanto insight, por maior que seja a sua evidência "racional", a afirmação do investigador não passa de uma hipótese, faltando-lhe evidência "material". Em outras palavras, o insight tem de ser testado empiricamente, como qualquer outra hipótese, tarefa que se enquadra dentro da metodologia das 
demais ciências empíricas. ${ }^{9}$

Para que uma hipótese seja aceita para exame, é preciso que ela seja confirmável/ falsificável, isto é, que especifique, tão claramente quanto possível, quais situações empíricas constituiriam evidência contra ou a favor dela. Se uma hipótese é compatível com toda e qualquer situação empírica, então ela não é confirmável/falsificável, embora, eventualmente, possa até ser verdadeira, mas não temos como sabê-lo. (Por exemplo: se tudo o que existe na natureza é fruto da evolução, então talvez a teoria que o afirme não seja falsificável; da mesma forma, se tudo o que há na sociedade é resultado da luta de classes, então essa teoria também não seria falsificável, creio). Testes são procedimentos que possibilitam o exame dessas evidências. Uma hipótese é testável se tais procedimentos são conhecidos e factíveis.

As hipóteses são testadas por experimentação, por observação sistemática, ou por ambos os métodos, dependendo da natureza do objeto sob análise. Sua aceitação ou rejeição finais dependem da empiria percebida. Se o critério de completa verificação apresenta problemas muito difíceis a esse respeito, o de graus de confirmação pode ser aceito. Assim, dependendo da qualidade e da quantidade da evidência existente, uma hipótese pode ser aceita ou rejeitada além de dúvidas razoáveis. Se aceita, ela é então chamada de 'lei'. Precisando mais o termo: por 'lei' entende-se uma generalização sintética verdadeira com pelo menos dois conceitos de conteúdo empírico preciso, que admita confirmação direta e indireta e cuja evidência não esteja contida em

\footnotetext{
Sobre o assunto, entre outras fontes, ver a breve discussão sobre verstehen feita por Richard Rudner, Philosophy of Social Science, En glewood Cliffs: Nova Jersey, 1966, p. 71-73. [Filosofia da ciência social, Rio de Janeiro: Zahar, 1969].
}

uma classe finita de observações. ${ }^{10}$

\section{Leis e teorias}

As leis podem relacionar conceitos de diferentes tipos: qualitativo (nominal), comparativo (ordinal) e quantitativo (intervalar ou razão/proporção). Conceitos comparativos e quantitativos são também chamados de variáveis, uma vez que possuem valores variáveis.

As leis podem especificar condições-limite, mas a evidência para elas não pode ser restrita a um conjunto finito de observações. As condições-limite, isto é, a especificação do que deve estar presente para que a lei se verifique, pertencem ao antecedente da lei, isto é, à cláusula "se". Nas ciências sociais, esses antecedentes incluem, geralmente, mas não necessariamente, parâmetros espaçotemporais.

As leis podem expressar relações universais ou, mais comumente, estatísticas (fatos ou eventos com a propriedade A têm certa probabilidade de possuírem também a propriedade B) entre os seus conceitos. Na verdade, o que se relaciona nas leis não são propriamente conceitos, mas as propriedades por eles referidas. Dizer que as leis relacionam conceitos é apenas uma maneira simplificada de abordar o assunto.

A evidência favorável a uma lei será sempre incompleta, porque não podemos examinar todos os fatos ou eventos a ela subsumíveis, já que estes não podem configurar um conjunto finito. Não podemos, logicamente, predizer que os fatos e eventos explicados pela lei continuarão a ocorrer no futuro, em-

- Ver Kelley, E. W. Causation, Statistical Association and Mathematical Models, Bloomington: Universidade de Indiana, 1967. Tese de doutoramento, inédita. 
bora, por razões práticas, façamos isso todo o tempo. Este é o problema da indução. Inversamente, evidências contrárias a uma lei nos levam necessariamente a descartá-la como falsa.

As leis causais são tipos especiais de leis: expressam, assimetricamente, uma sequência temporal entre seus conceitos: Se A em $\mathrm{t}$, então $\mathrm{B}$ em $\mathrm{t}_{1}$. Neste exemplo, lembrando Hume, diz-se que A causa $B$, mas não viceversa. A relação de causa e efeito não é um fenômeno observável. Ela é apenas inferida e atribuída pelo pesquisador, sendo assim logicamente incerta."

Quando se diz que uma hipótese passa a ser chamada de lei tendo em vista a qualidade e a quantidade da evidência a seu favor, é preciso entender que essa evidência é não apenas direta, mas também indireta. Diz-se que uma lei possui evidência indireta quando existe evidência direta para leis logicamente relacionadas com ela. Em outras palavras: quanto mais uma lei é integrada em uma teoria, tanto mais convincente será a sua aceitação. Por 'teoria' entenda-se um conjunto logicamente relacionado de leis. Esta última afirmação implica que não pode haver elaboração teórica desvinculada de investigação empírica. ${ }^{12}$

Ressalte-se, no entanto, que, do ponto de vista lógico, não se pode afirmar em defi-

\footnotetext{
Ver, a esse respeito, Hubert Blalok Jr., Causal Interferences in None xperimental Research, Chapel Hill: The University of North Carolina Press, 1961, p. 9-11. A tentativa de Blalock, entre outros, de refutação desta opinião é inadequada, dada a impossibilidade de definir o que ele entende por "agente produtor" (termo usado em substituição a "causa"), tendo em vista que, segundo o autor, tal conceito se refere a "algo que está acima do que pode ser expresso em linguagens formais".

2 Convém examinar a discussão, travada há vários anos, sobre orien tações metodológicas do trabalho sociológico no Brasil: A. O. Cintra, "Sociologia: ciência fática", Revista de Estudos Sociais, vol. 1, n. 1, 1965; d. "Sociologia e ciência", Revista Brasileira de Ciências Sociais, vol. 4, n. 1, 1966, p. 13-49; F. W. Reis, "A propósito de ciência e dialética", ib. p. 298-309; W. G. dos Santos, "Preliminares de uma controvérsia metodológica", Revista Civilização Brasileira, vol. 1, n. 5/6, 1966, p. 77-94. Ver também Carlos Estevam, "Construção de teoria na ciência socia brasileira", Dados, vol. 1, 1966, p. 84-114
}

nitivo que uma teoria é verdadeira, embora seja possível afirmar a sua falsidade. O que se pode dizer é que uma teoria conta com uma forte opinião favorável da comunidade científica, baseada em evidências empíricas confiáveis, obtidas ao longo do tempo. Sendo a ciência uma atividade social, a aceitação de ideias não depende da convicção do seu autor, mas do fato de elas sobreviverem à crítica dos seus pares. Dito de outra forma: as teorias são aceitas por sua adequação empírica para explicar e predizer a ocorrência de fatos ou eventos observáveis. Note-se que, ao contrário de leis e teorias, as proposições empíricas podem, sim, ser consideradas verdadeiras ou falsas além de qualquer dúvida razoável. (Se alguém duvidar não apenas da nossa capacidade de conhecer a realidade, mas da própria existência desta, então meIhor será dedicar-se a outra atividade).

Idealmente, as teorias deveriam ser formalizáveis. A formalização de uma teoria consiste na substituição de seus conceitos por símbolos (letras ou números). Quando a substituição é feita apenas por números, falamos em quantificação.

Segundo o que foi dito, as leis sobre o desenvolvimento político expressariam, universal ou estatisticamente, o relacionamento deste com outros conceitos bem definidos. Da mesma forma, as leis causais sobre o desenvolvimento político indicariam quais conceitos o causam, e de que maneira; ou, inversamente, quais conceitos são causados pelo desenvolvimento político e de que maneiras. Isto significa que se podem estudar tanto as causas quanto as consequências do desenvolvimento político. Uma teoria do desenvolvimento político consistiria em um conjunto logicamente relacionado dessas leis. 


\section{Explicação e predição}

Perguntar pela explicação de um fato ou evento é perguntar por uma lei na qual tal fato ou evento possa ser subsumido. Quando a lei ou leis envolvidas são universais, a explicação assume a forma de um argumento dedutivo, no qual as premissas (o explanans) compreendem as descrições dos fatos pertinentes e a enunciação da(s) lei(s) relevante(s), e a conclusão (o explanandum) apresenta a descrição do evento explicado. (Se todo A é B, então se x é A, x é B). Este é o modelo nomológico-dedutivo (ou "covering law model") de Hempel. ${ }^{13}$

Existem, portanto, dois critérios para decidir sobre a aceitação de uma explicação. O primeiro é puramente formal: dado o explanans, acaso o explanandum segue-se logicamente? O segundo é empírico: qual a qualidade da evidência oferecida para a(s) lei(s) envolvida(s) no explanans, de um lado, e qual a precisão das descrições dos fatos e eventos pertinentes, de outro? Se todos os elementos da premissa de um argumento dedutivo válido forem verdadeiros, então sua conclusão também o será. Do contrário, o argumento poderá ser logicamente válido, mas empiricamente falso.

A estrutura lógica da predição é igual, pelo menos neste caso, à da explicação. No caso da explicação, o explanandum já ocorreu e procura-se saber algo, ou tudo, sobre o explanans; no caso da predição, tem-se o explanans e procura-se afirmar a ocorrência do explanandum, seja no futuro, seja também no passado.

De forma similar, mas não inteiramente idêntica, pode-se falar da explicação de leis.

\footnotetext{
${ }^{3}$ Ver a discussão sobre "explicação dedutivo-nomológica" em Carl C. Hempel, Philosophy of Natural Science, Nova York, Prentice Hall, 1966 [Filosofia da ciência natural, s/indicação de tradutor, Rio de Janeiro: Zahar, 1969, p. 68-73]
}

Diz-se que uma lei é explicada quando ela pode ser subsumida em outra lei, ou leis. Isto significa que leis de baixo nível de generalidade são subsumidas em leis de maior generalidade, que por sua vez são subsumidas nos axiomas da teoria.

Finalmente, é de se notar que a busca de leis causais, e de teorias que as integrem, constitui o fim mais importante, ainda que não único, das ciências empíricas, porque quando as causas e efeitos dos fenômenos são conhecidos, então, pelo menos em princípio, será possível neles interferir.

De acordo com o exposto, explicar desenvolvimento político consistiria em subsumir tal fenômeno numa lei, ou leis. Estas poderiam ser universais ou estatísticas. Da mesma forma, explicar uma lei sobre desenvolvimento político consistiria em subsumi-la em outra lei, ou leis, de maior generalidade. A quantidade e a variedade de nosso conhecimento sobre o desenvolvimento político dependeriam, portanto, da quantidade e qualidade das leis eventualmente descobertas sobre o assunto. E quanto mais essas leis se integrassem em uma teoria do desenvolvimento político, tanto mais seguro seria o nosso conhecimento.

\section{Conclusão}

É importante distinguir entre a tarefa de reconstrução lógica da ciência, abordada neste artigo, e a de construção da ciência. A primeira se coloca em um nível de reflexão crítica, tendo por objeto a atividade científica em sua dimensão lógica. Ela pode, no entanto, sugerir ideias para a segunda tarefa, pois, do contrário, seria talvez uma atividade intelectual estéril. A discussão sobre a formação de conceitos e o problema dos 
"indicadores", por exemplo, parece ter implicações práticas bastante sensíveis, apesar dos múltiplos tropeços do autor não especializado em terreno tão pantanoso.

Como um todo, entretanto, o resultado da reconstrução lógica da ciência, se aplicado à tarefa de construção da ciência, seria muito mais uma camisa de força do que uma ajuda. Pois não resta dúvida de que o cientista, em seu trabalho, necessita de completa liberdade de ação com referência a quaisquer dogmas meta (ou para) científicos. 0 resultado desse trabalho, entretanto, tem de ser julgado segundo os padrões prevalecentes de excelência científica. Por isso, não pode o cientista abster-se de se informar sobre essas questões, com a ressalva de que uma preocupação excessiva com a metodologia de pesquisa pode diminuir o trabalho de pesquisa propriamente dito. Mas nem sempre se percebe uma linha divisória muito clara entre falar sobre o mundo (papel da ciência) e falar sobre a linguagem que utilizamos para falar sobre o mundo (papel da filosofia da ciência). Analogamente, podemos refletir sobre problemas filosóficos em geral e sobre o método utilizado para filosofar, objetivo este da metodologia filosófica ou metafilosofia. Em ambos os casos, a análise conceitual continua a ser o principal instrumento de trabalho da filosofia analítica.

O autor é doutor em ciência política pela Universidade de Chicago e professor-fundador e titular da FGV Direito Rio.

\section{Bibliografia Consultada}

Esta bibliografia, algo extensa para um artigo, objetivava chamar a atenção do leitor para obras que, com raras exceções, não eram lembradas ou mesmo conhecidas por autores brasileiros, em estudos sobre temas da lógica da metodologia de pesquisa, à época da publicação da versão original (1972). Em sua grande maioria, os autores selecionados possuem alguma identificação, em graus variados, com a orientação filosófica conhecida pelo nome de positivismo/empirismo lógico, desenvolvida em Viena nas décadas de 1920 e 1930. Com o início da II Guerra, seus membros se deslocaram para ótimas universidades inglesas e norte-americanas, onde deixaram marcas até hoje influentes. O leitor interessado poderá encontrar bibliografias exaustivas na maioria das coletâneas citadas. Informações sobre traduções para o português foram agora acrescentadas à bibliografia original.

Achinstein, Peter, e Stephen Barber (orgs.). (1969). The legacy of Logical Positivism, Baltimore: The John Hopkins Press.

Ammerman, Robert. (1965). Classics of Analytical Philosophy. Nova York: McGraw-Hill.

Austin, J. L. (1962). How to do Things with Words. Oxford: Claredon Press. [Quando dizer é Fazer, trad. D. Marcondes, Porto Alegre: Artes Médicas, 1990].

Ayer, Jules. (1946 [1935]). Language, Truth, and Logic. Mineola, NY: Dover

(org.). (1959). Logical Positivism. Nova York: The Free Press.

Bergmann, Gustav. (1957). Philosophy of Science. Madison: University of Wisconsin Press.

(1951). The logic of psychological concepts. Philosophy of Science, vol. 18, p. 93-110.

Black, Max. (1964). A Companion to Wittgenstein's Tractatus. Ithaca, NY: Cornell University Press.

Bloomfield, Leonard. (1969 [1939]). Linguistic Aspects of Science. International Encyclopedia of Unified Science, vol.1, n.4, Chicago: The University of Chicago Press.

Braithwaite, Richard B. (1953). Scientific Explanation. Londres e Nova York: Cambridge University Press. Braybrooke, David (org.). (1956). Philosophical Problems of the Social Sciences. Londres: MacMillan. Brodbeck, May. (1959). Models, Meaning, and Theories. In: Gross, op. cit., p. 373-403.

Carnap, Rudolph. (1959). The Elimination of Metaphysics Through Logical Analysis of Language. In: Ayer, 
Logical Positivism, op. cit., p. 60-81.

Empiricism, Semantics, and Ontology. In: Rorty, op. cit., p. 72-84.

(1967 [1928]). The Logical Structure of the World.

Los Angeles: University of California Press.

Testability and meaning. In: Feigl \& Brodbeck, op. cit., p. 47-92.

Chisholm, Roderick M. (1966). Theory of Knowledge. Upper Saddle River, NJ. [Teoria do Conhecimento, s/ indicação de tradutor, Zahar, 1969].

Danto, Arthur; Morgenbesser, Sidney (orgs.). (1960). Philosophy of Science: Meridian Books. Filosofia da ciência. (1975). Sem indicação de tradutor, São Paulo: Cultrix/Ed. USP.

Feigl, Herbert. (1967). The"Mental" and the "Physical": the essay and a postscript. Mineápolis: University of Minnesota Press.

\& May Brodbeck (orgs.). (1953). Readings in the Philosophy of Science. Nova York: Appleton, Century, Crofts.

\& Grover Maxwell (orgs.). (1961). Current Issues in the Philosophy of Science. Nova York: Holt, Rinehart \& Winston.

(1958). Minnesota Studies in the Philosophy of Science, Vol. II, Mineápolis: Minnesota University Press. (1962). Minnesota Studies in the Philosophy of Science, Vol. III, Mineápolis: University of Minnesota Press.

\& Michael Scriven (orgs.). (1956). Minnesota Studies in the Philosophy of Science. Vol.I, Mineápolis: University of Minnesota Press.

Flew, Antony (org.). (1964). Logic and Language. Nova York: Anchor Books.

Goldberg, Arthur; Gregor, James; Gunnell, John. (1969). Symposium on Scientific Explanation in Political Science. American Political Science Review, vol. LXIII, n. 4, p. 1233-1262.

Goodman, Nelson. (1951). The Structure of Appearance, Cambridge, Mass.: Harvard University Press.

Hegenberg, Leônidas. (1969). Explicação Científica. São Paulo: Herder.

Hempel, Carl G. (1965). Aspects of Scientific Explanation and Other Essays in the Philisophy of Science. Nova York: Free Press.

(1952). Fundamentals of Concept Formation in Empirical Science. International Encyclopedia of Unified Science, vol. II, n. 7. Chicago: The University of Chicago Press.

(1966). Philosophy of Natural Science. Nova York,
Prentice Hall. Filosofia da ciência natural. (1970). Sem indicação de tradutor, Rio de Janeiro: Zahar.

Joergenson, Joergen. (1951). The Development of Logical Empiricism. International Encyclopedia of Unified Science, vol. II, n. 9. Chicago: The University of Chicago Press.

Kuhn, Thomas S. (1962). The Structure of Scientific Revolutions. Chicago: The University of Chicago Press. A estrutura das revoluções científicas. (1975). Sem indicação de tradutor, São Paulo: Perpectiva.

Morgenbesser, Sidney; Suppes, P; White, M. (orgs.). (1969). Philosophy, Science, and Method. Nova York: St. Martin's Press.

Nagel, Ernest. (1961). The Structure of Science. Nova York: Harcourt, Brace \& World.

Suppes, P.; Tarski, A. (orgs.). (1962). Logic, Methodology, and Philosophy of Science. Stanford, Calif.: Stanford University Press.

Natanson, Maurice (org.). (1963). Philosophy of the Social Sciences. Nova York: Random House.

Neurath, Otto. (1944). Foundations of the Social Sciences., Chicago: Chicago University Press.

Sociology and Physicalism. In: Ayer, op. cit., p. 282-317.

Pap, Arthur. (1962). An Introduction to the Philosophy of Science. Nova York: Free Press.

Passmore, John. (1967). Logical Positivism. The Encyclopedia of Philosophy, vol. 5. Londres: MacMillan, p. 52-57.

Popper, Karl. (1965 [1935]). The Logic of Scientific Discovery, Nova York: Harper and Row. [A lógica da pesquisa científica (1998), trad. Leônidas Hegenberg e Octanny Silveira da Mota, São Paulo: Cultrix, $7^{a}$ ed.].

Przeworski, Adam, e Henry Teune. (1970). The Logic of Comparative Social Inquiry, Nova York: John Wiley \& Sons.

Quine, W. V. Orman. (1951). Two Dogmas of Empiricism, Philosophical Review, 60, p. 20-43.

(1963). From a Logical Point of View, Nova York: Harper \& Row.

Reichenbach, Hans. (1968). The Rise of Scientific Philosophy, Los Angeles: University of California Press.

Rorty, Richard (org.). (1967). The Linguistic Turn, Chicago: The University of Chicago Press.

Rudner, Richard. (1966). Philosophy of Social Science, Englewood Cliffs: Nova Jersey. [Filosofia da Ciência Social, Rio de Janeiro: Zahar, 1969].

Russell, Bertrand. (1940). An Inquiry into Meaning and Truth, Londres: Allen and Unwin. 
(1948). Human Knowledge: Its Scope and Limits, Londres: Allen and Unwin. [O conhecimento humano, sua finalidade e limites, s/indicação de tradutor, São Paulo: Cia. Ed. Nacional, 1958].

(1926). Our Knowledge of the External World, Londres: Allen and Unwin. [Nosso conhecimento do mundo exterior: estabelecimento de um campo para estudos sobre o método científico em filosofia, s/indicação de tradutor, São Paulo: Cia. Ed. Nacional, 1966]. Ryle, Gilbert. (2009 [1949; 1971]). The Concept of Mind and Collected Papers (Volumes I and II), Londres: Routledge \& Kegan Paul.

Salmon, Wesley. (1973). Logic, Nova York, Prentice Hall. [Lógica, trad. [Leônidas Hegenberg e Octanny Silveira da Mota, Rio de Janeiro: Zahar, $6^{a}$ ed., 1984].

Schlik, Moritz. The Future of Philosophy, in Rorty, op. cit., p. 43-53.

Toulmin, Stephen. (1953). The Philosophy of Science, Londres: Hutchinson.

Waismann, F. (2013[1967]). Wittgenstein und der Wiener Kreis, trad. [para o inglês] J. Schulte e B. McGinnis, Wittgenstein and the Vienna Circle, Oxford: Basil Blackwell.

Winch, Peter. (1958). The Idea of a Social Science and its Relation to Philosophy, Londres: Routledge \& Kegan Paul. [A ideia de uma ciência social, trad. Anísio Teixeira e Vera Freitas de Castro, São Paulo: Cia Ed. Nacional, 1970].

Wittgenstein, Ludwig. (1922 [1921]). Tractatus Logico -Philosophicus, edição bilíngue alemão/inglês, trad. [para o inglês] C. K. Ogden, Londres: Routledge \& Kegan Paul, [Tractatus logico-philosophicus, trad., apresentação e ensaio introdutório L. H. Lopes dos Santos, introdução Bertrand Russell, São Paulo: EdUSP, $3^{a}$ ed. 2001].

(1958). The Blue and Brown Books, edited by R. Rhees, Oxford: Basil Blackwell.

(1958 [1953]). Philosophical Investigations, trad. [para o inglês] G. E. M. Anscombe, Oxford: Basil Blackwell, [Investigações filosóficas, trad. Marcos G. Montagnoli, Petrópolis, RJ/Bragança Paulista, SP: Vozes/EdUSF, $9^{a}$ ed. 2014].

Friedman, Michael. (1999). Reconsidering Logical Positivism, Cambridge: Cambridge University Press.

Galavotti, Maria Carla (org.), Cambridge and Vienna. Frank Ramsey and the Vienna Circle. Dordrecht: Springer, 2006.

Hardcastle, Gary; Richardson, Alan (orgs.). (2003). Logical Empiricism in North America, Mineápolis: Universi- ty of Minneapolis Press.

Parrini, Paolo; Wesley, Salmon; Wesley, Merrilee (orgs.). (2003). Logical Empiricism. Historical and Contemporary Perspectives, Pittsburg, Pensilvânia: University of Pittsburg Press.

Pincock, Christopher. (2016). Logical Empiricism, in Cappelen, Herman, Tamar Szabó Gendler e John Hawthorne (orgs.), The Oxford Handbook of Philosophical Methodology, Nova York: Oxford University Press, p. 93-111.

Rescher, Nicholas (org.). (1985). The Heritage of Logical Positivism, Lanham, MD: University Press of America. (2006). The Berlin School of Logical Empiricism and its Legacy, Erkenntnis, 64, p. 281-304.

Richardson, Alan; Uebel; Thomas (orgs.). (2007). The Cambridge Companion to Logical Empiricism, Cambridge: Cambridge University Press.

Sarkar, Sahotra (org.). (1996). The Legacy of the Vienna Circle: Modern Reappraisals, Nova York: Garland.

Stadler, Friedrich. (2001 [1997]). The Vienna Circle: Studies in the Origins, Development, and Influence of Logical Empiricism, Vienna Circle Institute Library, Viena e Nova York: Springer. Edição abreviada e revista, Nova York: Springer, 2005.

(org.). (2003). The Vienna Circle and Logical Empiricism. Re-evaluation and Future Perspectives, Vienna Circle Institute Yearbook, Dordrecht-Boston -Londres: Kluwer.

Uebel, Thomas. (2013). Logical Positivism - Logical Empiricism: What's in a Name?, Perspectives of Science, 21, p. 58-99.

(2016). Vienna Circle, The Stanford Encyclopedia of Philosophy (Spring 2016 Edition), Edward N. Zalta (org.), Disponível em: <https://plato.stanford.edu/ archives/spr2016/entries/vuienna-circle/>.

Data de submissão: 19/03/2019

Data de aceite: 26/04/2019 